\title{
Prognostic predictors of lymph node metastasis in penile cancer: a systematic review
}

\author{
David S. Zekan ${ }^{1}$, Ahmad Dahman ${ }^{1}$, Ali J. Hajiran 2 ${ }^{2}$, Adam M. Luchey ${ }^{1}$, Jad Chahoud ${ }^{2}$, Philippe E. Spiess ${ }^{2}$ \\ ${ }^{1}$ Department of Urology, West Virginia University, Morgantown, WV, USA; ${ }^{2}$ Department of Genitourinary \\ Oncology, H. Lee Moffitt Cancer Center \& Research Institute, Tampa, FL, USA
}

\section{ABSTRACT}

Purpose: Squamous cell carcinoma (SCC) of the penis is a rare disease in developed countries but is associated with significant morbidity and mortality. A crucial prognostic factor is the presence of inguinal lymph node metastases (ILNM) at the time of diagnosis. At least 25\% of cases have micrometastases at the time of diagnosis. Therefore, we performed a literature review of studies evaluating factors, both clinical and pathological, predictive of lymph node metastases in penile SCC.

Materials and methods: Studies were identified using PubMed and search terms included the following: penile cancer, penile tumor, penile neoplasm, penile squamous cell carcinoma, inguinal lymph node metastasis, lymph node metastases, nodal metastasis, inguinal node metastasis, inguinal lymph node involvement, predictors, and predictive factor. The number of patients and predictive factors were identified for each study based on OR, HR, or RR in multivariate analyses, as well as their respective significance values. These were compiled to generate a single body of evidence supportive of factors predictive of ILNM in penile SCC. Results: We identified 31 studies, both original articles and meta-analyses, which identified factors predictive of metastases in penile SCC. The following clinical factors were predictive of ILNM in penile SCC: lymphovascular invasion (LVI), increased grade, increased stage (both clinical and pathological), infiltrative and reticular invasion, increased depth of invasion, perineural invasion, and younger patient age at diagnosis. Biochemically, overexpression of p53, SOD2, Ki-67, and ID1 were associated with spread of SCC to inguinal lymph nodes. Diffuse PD-L1 expression, increased SCC-Ag expression, increased NLR, and CRP > 20 were also associated with increased ILNM. Conclusions: A multitude of factors are associated with metastasis of SCC of the penis to inguinal lymph nodes, which is associated with poor clinical outcomes. The above factors, most strongly LVI, grade, and node positivity, may be considered when constructing a nomogram to risk-stratify patients and determine eligibility for prophylactic inguinal lymphadenectomy.
ARTICLE INFO

Ali Hajiran

http://orcid.org/0000-0002-1465-9821

Keywords:

Penile Neoplasms; Lymphatic

Metastasis; Health Belief Model

Int Braz J Urol. 2021; 47: 943-56

Submitted for publication:

October 21, 2020

Accepted after revision:

October 23, 2020

Published as Ahead of Print: January 20, 2021

\section{INTRODUCTION}

Squamous cell carcinoma (SCC) of the penis is a rare yet distressing condition associated with significant morbidity and mortality. In developing countries, however, this rate remains higher at up to 4.4 per 100.000 men. This is commonly attributed to a lower rate of circumcision and poor hygiene. It is especially rare in developed countries; the incidence in the United States is 0.81 cases per 100.000 men (1). Inguinal lymph nodes are not only the first site of metastatic spread, but also 
a crucial prognostic factor associated with penile SCC (2). Therefore, an accurate algorithm for screening and predicting lymph node involvement is crucial to management.

The $25 \%$ likelihood of micrometastatic disease at time of presentation of penile SCC creates further management dilemmas (2). 2020 National Comprehensive Cancer Network (NCCN) guidelines for management of non-palpable inguinal lymph node penile cancer include surveillance if low risk (cTis, cTa, cT1a) and chest/abdomen/pelvic imaging followed by inguinal lymph node dissection or dynamic sentinel lymph node biopsy (DSLNB) if intermediate or high risk (cT1b, cT2 or higher) (3). European Association of Urology (EAU) concur that lymph node staging should be offered if lymph nodes are nonpalpable and the patient is intermediate or high risk (4).

Prophylactic inguinal lymphadenectomy, while providing the best survival in clinically node-negative patients, can be overtreatment in patients that do not have micrometastases due to the high morbidity associated with the surgery. Studies have shown up to a $25 \%$ complication rate with the procedure, including skin necrosis, wound infection, lymphedema, seroma, lymphocele, and deep vein thrombosis $(5,6)$. Factors associated with higher risk of inguinal lymph node metastasis (ILNM) include higher pathologic tumor stage, higher grade, vascular or lymphatic invasion, and specific histologic features. However, identifying reliable predictors of metastasis, specifically micrometastasis, is crucial in the management of penile cancer. Therefore, we conducted a systematic review evaluating recent literature to better understand predictors of penile SCC LNM.

\section{MATERIALS AND METHODS}

This systematic literature review was conducted using studies performed between 2000 and 2020. Searches were conducted using PubMed and search terms included the following: penile cancer, penile tumor, penile neoplasm, penile squamous cell carcinoma, inguinal lymph node metastasis, lymph node metastases, nodal metastasis, inguinal node metastasis, inguinal lymph node involvement, predictors, and predictive factor.
All studies pertinent to the topic were reviewed, and references meeting our inclusion criteria not generated by our PubMed search were manually extracted and reviewed as available.

Eligible studies for inclusion within this systematic review were selected based on the following: 1) precise definition of predictors; 2) sufficient sample size to generate statistically significant predictors of LNMs; 3) pathologically-confirmed LNMs; 4) English studies performed with human subjects; 5) Studies performed after 2000 ; 6) Studies analyzing SCC of the penis as opposed to other penile neoplasms.

Definitions of several predictors were defined as previously published (2). Clinically positive inguinal lymph nodes $(\mathrm{cN}+)$ were defined as those that are palpable or visible with imaging examinations. Histological grade was divided into three groups: G1 (well-differentiated), G2 (moderately differentiated), and G3 (poorly differentiated). TNM staging used was based on that defined by the NCCN penile cancer guidelines (3). Comparison of stages to reach statistically significance varied between studies (Table-1). Growth pattern was classified as superficial or vertical; Invasion depth was measured from the intact basement membrane at the edge of the primary tumor to the deepest infiltrating tumor cell. LVI was defined as the presence of cancer in the lymphatic or vascular lumen that was detected by immunohistochemical staining (2). Histopathological subtypes were classified as low risk (verrucous, papillary, and warty), intermediate risk (usual SCCs and mixed forms), and high risk (basaloid, sarcomatoid, adenosquamous, and poorly differentiated types) according to EAU guidelines (4). PD-L1, Ki-67, SOD1, and ID1 expression and P53 immunohistochemistry were measured in tumor. CRP, NLR, and SCC-Ag were measured in serum (2). Apparent diffusion capacity was obtained on diffusion-weighted MRI of the penis and pelvis (7).

Numbers of subjects $(\mathrm{N})$ within individual original research articles were extracted as well as number of lymph node metastases (\#LN; as available). Statistically significant and insignificant prognosticators (with p-values) were also collected. 
Table 1 - Original studies reviewed with factors examined for lymph node metastasis and corresponding statistical significance on multivariate analysis.

Original Studies

\begin{tabular}{|c|c|c|c|c|c|c|}
\hline Study & $\begin{array}{l}\text { Patients } \\
\text { (N) }\end{array}$ & $\begin{array}{c}\text { Definition } \\
\text { of LNM }\end{array}$ & $\begin{array}{l}\text { LNM } \\
\text { (n) }(\%)\end{array}$ & Predictors of LNM & OR $(95 \% \mathrm{Cl})$ & p-value (multivariate) \\
\hline \multirow{8}{*}{$\begin{array}{l}\text { Peak et. al. } \\
\text { (2019) (1) }\end{array}$} & \multirow{8}{*}{1636} & \multirow{9}{*}{ NR } & \multirow{9}{*}{ NR } & Grade: & & 0.002 \\
\hline & & & & G2 (vs. G1) & $2.58(1.39-4.79)$ & \\
\hline & & & & G3-4 (vs. G1) & $3.27(1.70-6.29)$ & \\
\hline & & & & LVI & $2.49(1.61-3.84)$ & $<0.0001$ \\
\hline & & & & $\mathrm{cN}+:$ & $20.0(11.4-35.7)$ & $<0.0001$ \\
\hline & & & & N1 vs. N0 & $27.8(14.1-55.6)$ & \\
\hline & & & & N2 vs. N0 & $49.2(14.8-162.8)$ & \\
\hline & & & & N3 vs. NO & & \\
\hline \multirow{4}{*}{$\begin{array}{l}\text { Qu et. al. (2018) } \\
\text { (5) }\end{array}$} & \multirow{4}{*}{380} & & & Age $\leq 60$ & $0.68(0.52-0.88)$ & 0.003 \\
\hline & & \multirow{3}{*}{$\geq \mathrm{N} 1$} & \multirow{3}{*}{$63(17)$} & $\geq T 1 b$ & $3.32(1.38-8.01)$ & 0.0075 \\
\hline & & & & G2 (vs. 1) & $2.98(1.26-7.62)$ & 0.023 \\
\hline & & & & G3 (vs. 1) & $3.97(1.32-11.9)$ & 0.014 \\
\hline \multirow{7}{*}{$\begin{array}{l}\text { Maciel et. al. } \\
\text { (2019) (34) }\end{array}$} & \multirow{7}{*}{65} & \multirow{7}{*}{$\geq \mathrm{N} 1$} & \multirow{7}{*}{$24(37)$} & T2a & $0.341(0.111-1.049)$ & 0.061 \\
\hline & & & & $\mathrm{T} 2 \mathrm{~b}$ & $2.20(0.399-12.120)$ & 0.365 \\
\hline & & & & T3 & $0.075(0.012-0.462)$ & 0.005 \\
\hline & & & & G2 & $0.731(0.282-1.893)$ & 0.518 \\
\hline & & & & G3 & $1.489(0.145-15.235)$ & 0.737 \\
\hline & & & & LVI & $5.965(0.857-41.507)$ & 0.071 \\
\hline & & & & P53 expression & $1.789(0.602-5.318)$ & 0.296 \\
\hline \multirow{7}{*}{$\begin{array}{l}\text { Zhu et. al. } \\
\text { (2007) (19) }\end{array}$} & \multirow{7}{*}{73} & \multirow{7}{*}{$\geq \mathrm{N} 1$} & \multirow{7}{*}{$30(41)$} & $\geq \mathrm{T} 2$ & NR & 0.079 \\
\hline & & & & $\geq \mathrm{G} 2$ & NR & 0.118 \\
\hline & & & & LVI & 5.35 (1.009-28.313) & 0.049 \\
\hline & & & & High p53 & $6.01(1.402-25.764)$ & 0.016 \\
\hline & & & & High Ki-67 & $N R$ & 0.861 \\
\hline & & & & High E-cadherin & NR & 0.089 \\
\hline & & & & High MMP-9 & NR & 0.852 \\
\hline
\end{tabular}




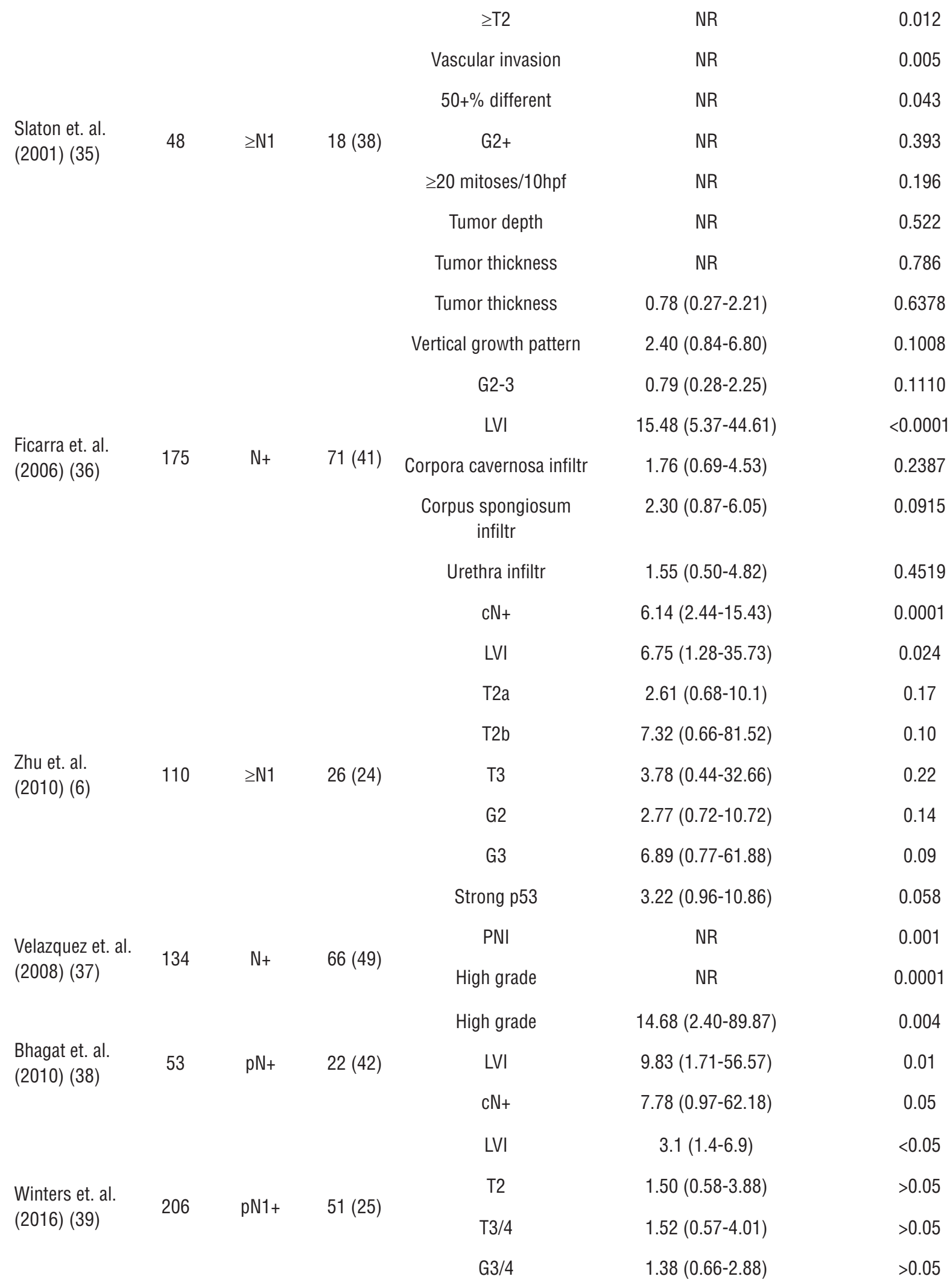




\begin{tabular}{|c|c|c|c|c|c|c|}
\hline & & & & LVI & $2.173(1.094-4.320)$ & 0.027 \\
\hline & & & & Grade: & & 0.011 \\
\hline & & & & Intermediate & $3.309(1.223-8.949)$ & \\
\hline Graafland et al & & & & Poor & $4.874(1.730-13.730)$ & \\
\hline (2010) (40) & 342 & $\mathrm{INt}$ & $00(\angle U)$ & $\begin{array}{l}\text { Corpus spongiosum } \\
\text { invasion }\end{array}$ & $1.465(0.738-2.909)$ & 0.28 \\
\hline & & & & $\begin{array}{c}\text { Corpus cavernosum } \\
\text { invasion }\end{array}$ & $1.591(0.782-3.234)$ & 0.20 \\
\hline & & & & Urethral invasion & $0.906(0.360-2.279)$ & 0.83 \\
\hline & & & & $\geq T 1 b$ & $2.67(1.16-6.15)$ * & 0.02 \\
\hline $\begin{array}{l}\text { Fonseca et. al. } \\
\text { (2013) (8) }\end{array}$ & 82 & $\mathrm{~N}_{+}$ & $46(56)$ & LVI & $2.09(1.03-4.22)$ * & 0.04 \\
\hline & & & & Infiltrative invasion & $2.00(1.00-4.03)$ * & 0.03 \\
\hline & & & & T2-3 (vs. 1) & NR & 0.004 \\
\hline $\begin{array}{l}\text { Dai et. al. } \\
\text { (2006) (41) }\end{array}$ & 72 & $\geq \mathrm{N} 1$ & $23(32)$ & $\mathrm{G} 2 / 3$ & NR & 0.207 \\
\hline & & & & Tumor depth & NR & $<0.001$ \\
\hline & & & & Tumor depth & NR & 0.03 \\
\hline & & & & Vascular invasion & NR & 0.02 \\
\hline Emerson et. al. & $2 ?$ & $>N 1$ & $10(15)$ & Age & NR & 0.24 \\
\hline (2001) (42) & & & (70) & Stage & NR & 0.28 \\
\hline & & & & Grade & NR & 0.53 \\
\hline & & & & Carcinoma in situ & NR & 1.00 \\
\hline & & & & $\mathrm{cN}+$ & $8.9(2.7-29.2)$ & $<0.001$ \\
\hline Termini et. al. & 125 & $\mathrm{~N}+$ & $44(35)$ & PNI & $9.6(2.7-33.6)$ & $<0.001$ \\
\hline (2015) (10) & & & & Tumor depth & $11.6(1.4-97.1)$ & 0.023 \\
\hline & & & & SOD2 overexpression & $3.4(1.1-10.1)$ & 0.029 \\
\hline & & & & LVI & $7.224(0.831-22.730)$ & 0.029 \\
\hline & & & & Absent koilocytosis & $0.088(2.628-50.718)$ & 0.001 \\
\hline Nascimento et. & 55 & $\mathrm{pN+}+\mathrm{N}_{+}$ & $28(51)$ & Grade & $2.333(0.101-2.232)$ & 0.288 \\
\hline al. (2020) (14) & & & & $\mathrm{CN}+$ & $1.106(0.023-0.821)$ & 0.888 \\
\hline & & & & PNI & $0.24(0.126-2.488)$ & 0.099 \\
\hline & & & & Stage & $1.389(0.124-2.017)$ & 0.649 \\
\hline
\end{tabular}




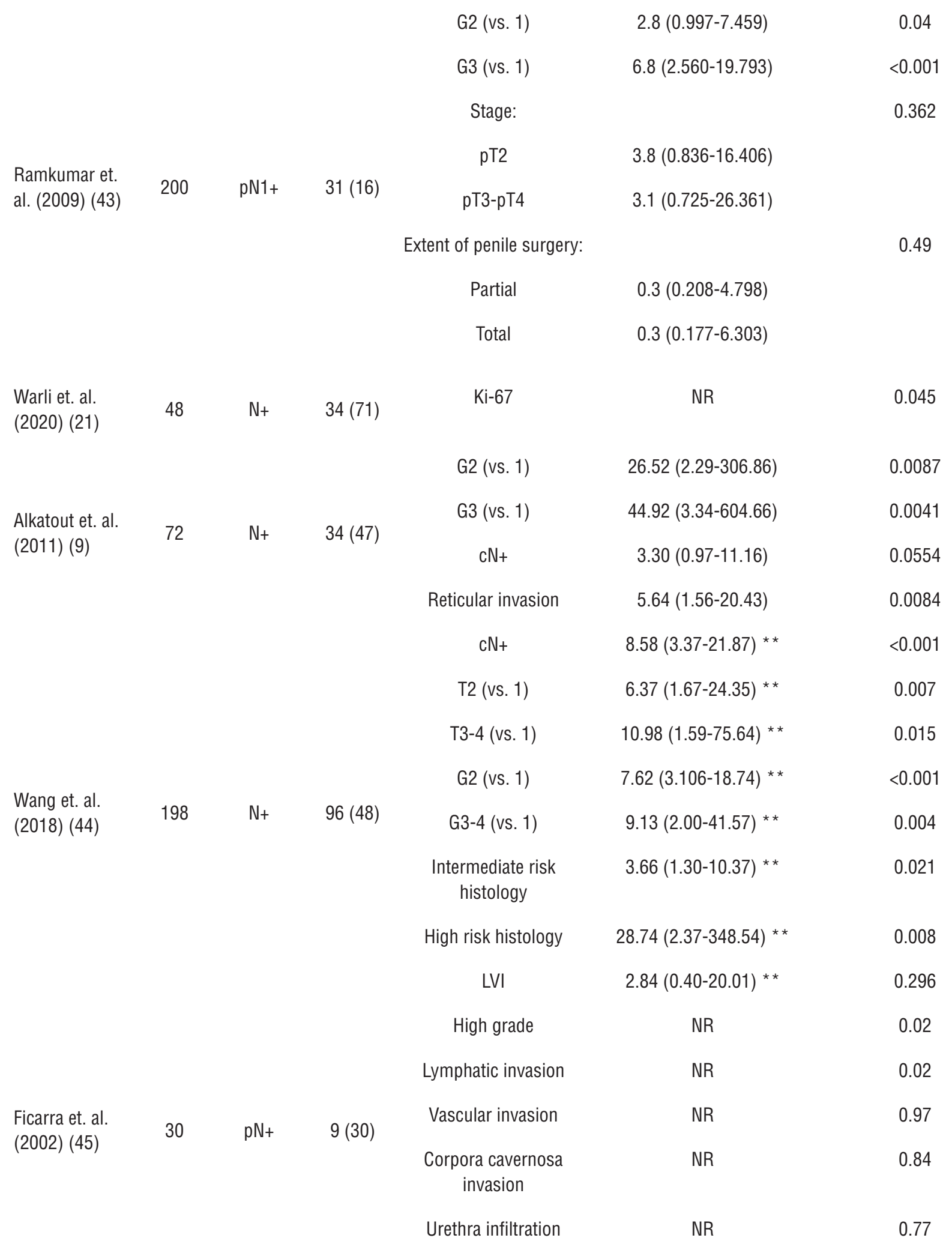




\begin{tabular}{|c|c|c|c|c|c|c|}
\hline \multirow{6}{*}{$\begin{array}{l}\text { Al Ghazal et. } \\
\text { al. (2013) } \\
(22)\end{array}$} & \multirow{6}{*}{51} & \multirow{6}{*}{$\mathrm{N}_{+}$} & \multirow{6}{*}{$16(31)$} & $\mathrm{CRP}>20$ & NR & 0.04 \\
\hline & & & & Residential area & NR & 0.5 \\
\hline & & & & BMI & NR & 0.9 \\
\hline & & & & Age & NR & 0.9 \\
\hline & & & & Stage & $N R$ & 0.01 \\
\hline & & & & Grade & $N R$ & 0.1 \\
\hline \multirow{3}{*}{$\begin{array}{l}\text { Zhou et. al. } \\
\text { (2020) (46) }\end{array}$} & \multirow{3}{*}{75} & \multirow{3}{*}{$\geq \mathrm{N} 1$} & \multirow{3}{*}{$31(41)$} & G3-4 (vs. 1) & $6.467(1.241-33.684)$ & 0.027 \\
\hline & & & & LVI & $5.162(1.056-25.243)$ & 0.043 \\
\hline & & & & $\begin{array}{l}\text { Short diameter to largest } \\
\text { clinical LN }\end{array}$ & $1.349(1.133-1.606)$ & 0.001 \\
\hline \multirow{3}{*}{$\begin{array}{l}\text { Unadkat et. } \\
\text { al. (2020) } \\
\text { (47) }\end{array}$} & \multirow{3}{*}{590} & \multirow{3}{*}{$\mathrm{pN+}$} & \multirow{3}{*}{$142(24)$} & G2 (vs. 1) & 2.16 & 0.02 \\
\hline & & & & G3-4 (vs. 1) & 2.81 & $<0.001$ \\
\hline & & & & LVI & 3.12 & $<0.001$ \\
\hline $\begin{array}{l}\text { Ottenhoff et. } \\
\text { al. (2017) } \\
(17)\end{array}$ & 213 & $\mathrm{N+}$ & $66(31)$ & $\begin{array}{l}\text { Diffuse PD-L1 } \\
\text { expression }\end{array}$ & NR & $<0.01$ \\
\hline \multirow{3}{*}{$\begin{array}{l}\text { Guimaraes } \\
\text { et. al. (2006) } \\
\text { (48) }\end{array}$} & \multirow{3}{*}{112} & \multirow{3}{*}{$\mathrm{N+}$} & \multirow{3}{*}{$55(49)$} & $\mathrm{cN+}$ & $3.83(1.4-10.0)^{\star}$ & $<0.05$ \\
\hline & & & & Lymphatic invasion & $3.95(1.5-10.4)$ * & $<0.05$ \\
\hline & & & & Infiltrating invasion & $4.18(1.5-11.3)^{\star}$ & 0.005 \\
\hline \multirow{2}{*}{$\begin{array}{l}\text { Luchey et. al. } \\
\text { (2014) (49) }\end{array}$} & \multirow{2}{*}{51} & \multirow{2}{*}{$\mathrm{pN+}$} & \multirow{2}{*}{$31(61)$} & Radiograph LN & NR & 0.001 \\
\hline & & & & Age $<65$ & $N R$ & 0.049 \\
\hline $\begin{array}{l}\text { Li et. al. } \\
\text { (2019) (50) }\end{array}$ & 891 & N1-N3 & $166(19)$ & LVI & NR & $<0.001$ \\
\hline \multirow{2}{*}{$\begin{array}{l}\text { Lopes et. al. } \\
\text { (2002) (20) }\end{array}$} & \multirow{2}{*}{82} & \multirow{2}{*}{$\mathrm{N+}$} & \multirow{2}{*}{$42(51)$} & p53 overexpression & $4.8(1.6-14.9)$ * & $<0.05$ \\
\hline & & & & Lymphatic embolization & $9.4(2.8-31.6)$ * & $<0.05$ \\
\hline $\begin{array}{l}\text { Barua et. al. } \\
\text { (2018) (7) }\end{array}$ & 26 & $\mathrm{~N}+$ & NR & $\begin{array}{l}\text { Apparent diffusion } \\
\text { capacity on DW-MRI }\end{array}$ & $N R$ & 0.001 \\
\hline $\begin{array}{l}\text { Hu et. al. } \\
\text { (2019) (51) }\end{array}$ & 64 & $\mathrm{N+}$ & $26(41)$ & ID1 overexpression & NR & 0.007 \\
\hline
\end{tabular}

${ }^{*} \mathrm{RR} ;{ }^{* *} \mathrm{HR}$

$\mathbf{L V I}=$ lymphovascular invasion; $\mathbf{P N I}=$ perineural invasion; $\mathbf{c N}+$ = clinically node positive; $\mathbf{p N +}=$ pathologically node positive; $\mathbf{M} \mathbf{M P}-\mathbf{9}=$ matrix metalloprotease $9 ; \mathbf{S O D 2}$ = superoxide dismutase 2; PD-L1 = programmed death-ligand 1; ID1 = DNA-binding protein inhibitor ID-1 


\section{RESULTS}

Original research articles analyzing clinical, histopathologic, and biochemical predictors of LNMs in SCC of the penis are presented in Table-1, including number of patients within the study $(\mathrm{N})$, definition of positive lymph nodes, number of patients with LNMs (n), percentage of metastases within the study population (\%), and factor(s) shown to be predictive of lymph node metastases within the study (with p-value). Statistically significant predictors present in greater than one study are shown in Table-2, with total number of patients and lymph nodes presented as available within the reviewed manuscripts.

\section{Clinical/Pathological Factors}

Factors known to worsen prognosis for patients with SCC of the penis correlate strongly with positive lymph node(s) on inguinal lymphadenectomy. Namely, on our review, lymphovascular invasion was shown in both the highest number of studies and patients to correlate with lymph node metastases in patients with SCC of the penis. In their analysis of 1636 patients, all of whom had pathological lymph node staging, Peak et al. demonstrated lymphovascular invasion in $20.6 \%$ of patients with odds ratio (OR) of 2.49 (1). Similarly, higher grade and stage, as well as clinically positive nodes on exam were shown to be predictors of positive pathological involvement of lymph nodes. Specifically, 47.4\% of patients were G2 and 31.7\% G3-4, with respective ORs of 2.58 and 3.27. Both pathological and clinical staging were significant predictors of LNM in this study, with OR of 1.61 and 1.50 in p2 vs. p3/4 and 23.3, 43.5, and 76.0 in cN1, $\mathrm{cN} 2$, and cN3, respectively (1). Although less reported, infiltrative $(\mathrm{RR}=2.68$; present in $70.2 \%$ with ILNM) and reticular invasion (present in 64\% with ILNM) of the primary lesion on pathologic examination were also significant predictors of positive lymph nodes in SCC of the penis $(8,9)$. Finally, increased depth of invasion, perineural invasion, and decreased patient age at diagnosis were shown to have predictive value; 90\% patients with tumor depth $<=5 \mathrm{~mm}$ had ILNM, while $48.8 \%>5 \mathrm{~mm}$ had metastases. Similarly, $73.5 \%$ of patients with perineural invasion had ILNM compared to $24.4 \%$ without perineural invasion (10). Age varies amongst studies, but Qu et al. note the average age at diagnosis in patients with ILNM to be 62 compared to 69 in those without (5).

A common, and seemingly reasonable, method for determination of patients who should

Table 2 - Quantity of clinical/pathological markers found to be significant amongst all studies.

Quantity of clinical/pathological markers:

\begin{tabular}{lcc}
\hline Predictor & Studies & Patients with ILNM/ Total patients (\%) \\
\hline LVI & 17 & $815 / 2946(28)$ \\
Grade & 11 & $606 / 2074(29)$ \\
CN+ & 8 & $295 / 611(48)$ \\
Stage & 6 & $270 / 845(32)$ \\
Invasion pattern & 3 & $148 / 266(56)$ \\
Tumor depth & 3 & $77 / 219(35)$ \\
Age & 2 & $94 / 431(22)$ \\
PNI & 2 & $110 / 259(42)$ \\
\hline
\end{tabular}


undergo a full inguinal lymph node dissection is through the use of dynamic sentinel lymph node biopsy (DSLNB). The NCCN and EAU both recommend use of DSLNB in patients with intermediate- and high-risk disease who have non-palpable inguinal nodes on clinical exam. Based on their literature review and nomogram, Peak et al. suggest that this should only be performed in centers specialized in lymph node mapping by clinicians who focus in penile cancer (1). This is due to a reported 6\% false-negative rate reported by Lam et al. (11). Another group performing similar work using a large institutional database cited a 7\% false-negative rate and noted the cost associated with DSLNB may outweigh the benefit of extended inguinal node dissection. Schubert et al. performed a smaller study (32 patients) with sentinel node sampling followed by inguinal node dissection in positive cases according to EAU guidelines and showed no false negatives (12). Underscored throughout are the risks associated with DSLNB, which are similar albeit less severe than those associated with a full inguinal dissection and occur at a rate of 7.6\%: wound infection, lymphocele, and hematoma (11). Dell'Oglio et al. suggest that a combination radioactive (99mTc-nannocolloid) and fluorescent (indocyanine green) tracer can increase the sensitivity of DSLNB over regular a combination of radiotracer and blue dye. Specifically, in a cohort of 400 patients, they showed a $39 \%$ higher sentinel node detection rate, further increasing the sensitivity of this nodal detection measure and its clinical utility (13).

Interestingly, one study showed that absence of koilocytosis (seen in epithelial cells with HPV infection) was predictive of metastasis; specifically, $32.2 \%$ of patients with histological koilocytosis had positive nodes compared to $82 \%$ without koilocytosis (14). Also, a more easily obtained, but less studied factor that correlates with metastasis is the apparent diffusion coefficient (ADC) on diffusion-weighted MRI (DW-MRI) of the primary tumor, which shows the changes in proton mobility when there is underlying pathology or tissue alteration. ADC is lower in the setting of lymph node metastases, even when nodes are of normal size; one study yielded a sensitivity of
$100 \%$ and positive predictive value of $84.61 \%$ (7) Other advances with MRI in the detection of ILNM in penile cancer involve the use of ultra-small superparamagnetic iron oxide particles (USPIO) as contrast agents. These agents are taken up by penile lymphatics and phagocytosed by resident macrophages; these macrophages are less prevalent in metastatic nodes. In a limited study with seven men (stage T1b-T2), this detection method showed sensitivity of $100 \%$, specificity of 97\%, positive predictive value of $81.2 \%$, and negative predictive value of $100 \%(15,16)$. This provides promise as $\mathrm{PET} / \mathrm{CT}$ is only $57 \%$ accurate in predicting ILNM in patients with normal groin exams compared to $96 \%$ in patients with palpable nodes (17). Conventional imaging modalities rely on size criteria ( $>8-10 \mathrm{~mm})$ to diagnose ILNM. In patients who are low-risk for ILNM, an $8 \mathrm{~mm}$ cut-off in the CT short axis provides the most accurate detection, with a sensitivity of $87 \%$ and a specificity of $81 \%$. For patients with high risk for ILNM, size is less accurate, and the most accurate $(88 \%)$ criteria for nodal involvement is an irregular nodal border with a specificity of 95\% (15). Moving away from size criteria for the evaluation of ILNM in the presence of known primary SCC of the penis is crucial, as this has the tendency to miss occult metastases in normal-sized nodes and to label reactive nodes as malignant. This led Singh et al. to label overall cross sectional imaging (CT and MRI) detection of ILNM with a sensitivity of $40-60 \%$ and a false negative rate of $10-20 \%$. However, these imaging methods are helpful in detecting metastases in the pelvis/retroperitoneum and in patients whose body habitus limit physical examination (18).

\section{Biochemical Factors}

Less studied predictors of LNM in SCC of the penis that remained statistically and clinically significant were noted in individual studies for the purposes of this review. The majority of these studies are biochemical markers shown to be under- or over-expressed in the tumor or blood of study subjects. Namely, tumor suppressor p53 overexpression was shown to predict migration of primary tumors to inguinal lymph nodes $(19,20)$. The antioxidant and tumor sup- 
pressor superoxide dismutase (SOD2) overexpression (overexpression=present in $>50 \%$ of cells; seen in $44.8 \%$ of penile SCCs) was also predictive of lymph node involvement: 52.8\% of patient with nodal involvement had the above criteria for overexpression compared to $24.6 \%$ with $<50 \%$ of cells overexpressing (10). Warli et al. recently reported that overexpression ( $>20 \%$ of nuclei) of the nuclear proliferative protein $\mathrm{Ki}-67$ is associated with increased movement of SCC of the penis to inguinal lymph nodes independent of tumor stage and grade (21). Diffuse PD-L1 expression is significantly predictive, which serves as a clinically relevant marker because of recent advancements targeting PD-L1 with immunotherapeutic agents (17). Tumor overexpression of ID1, which encodes a DNA-binding protein inhibitor (effectively eliminating its DNA-binding ability) is also known to predict node metastasis. Blood level of CRP $>20 \mathrm{mg} / \mathrm{dL}$ was the only predictive factor in the original research articles reviewed that could be detected in the serum (22).

\section{Pertinent Meta-Analyses}

Various other reviews have sought to define primary tumor characteristics predictive of lymph node metastasis in order to better define the need for prophylactic inguinal lymphadenectomy in SCC of the penis, many of which overlap with the above original studies. Namely, Ficarra et al. suggest histologic subtype, pathologic extension, histologic grade, and lymphatic and/or venous embolization are the most important factors (23). Specifically, basaloid SCC, >pT1, and $>\mathrm{G} 1$ predict higher risk of lymph node metastasis and poor prognosis. Lymphatic embolization is a pathologic diagnosis with nests of carcinomatous cells in a lumen with thin walls, without smooth muscle fibers or red blood cells. The same condition with red blood cells or smooth muscle fibers is considered venous embolization, both of which suggest the need for inguinal lymphadenectomy (24). Hu et al. performed a meta-analysis of retrospective studies and showed both clinicopathologic and biochemical markers to be associated with increased risk of inguinal LNM (2). In addition to the clinicopathologic factors cited by Ficarra et al., they showed positive clinical nodes, vertical growth, tumor size $(>3 \mathrm{~cm})$, invasion depth $(>5 \mathrm{~mm})$, and nerve, corporal, and urethral invasion to be predictors of lymph node metastasis. They also added higher neutrophil-to-lymphocyte ratios (NLR) and squamous cell carcinoma antigen (SCC-Ag) overexpression to the above list of biochemical predictors (23). Zhou et al. performed a meta-analysis of exclusively perineural invasion and its ability to predict inguinal lymph node metastasis; they showed a statistically significant higher rate of LNM in penile SCC with perineural invasion compared to that in which nerve invasion is absent (25).

\section{DISCUSSION}

Development of an algorithm capable of accurately predicting ILNM in patients with SCC of the penis is crucial, as adequate lymph node dissection has been established to improve survival in these patients for almost forty years (26). Most of the above clinicopathologic factors associated with increased risk of SCC of the penis metastasis to inguinal lymph nodes are intuitive and already established as factors making the disease intermediate- or high-risk according to the NCCN. In patients with non-palpable inguinal lymph nodes, this includes T1b disease and any disease T2 or higher (3). As above, these patients are candidates for DSLNB per the NCCN and EUA. In patients with palpable inguinal nodes, the NCCN suggests movement straight to ILND if the lesion is high risk: T1, high-grade, lymphovascular invasion, perineural invasion, or $>50 \%$ poorly differentiated. Percutaneous biopsy is only suggested in patients with low risk disease (3). Essentially, our review concurs with and further compliments the NCCN guidelines with addition of the following clinically- and pathologically significant factors: decreased patient age at diagnosis, absence of koilocytosis, and decreased apparent diffusion coefficient on DW-MRI. Although further cost analyses need to be performed for the latter, age and koilocytosis on pathological section provide easily obtained measures to increase clinical suspicion of ILNM in patients with diagnosed SCC 
of the penis. With regard to imaging, EAU guidelines state that longitudinal/transverse diameter ratio and absence of the lymph node hilum are highly specific findings on ultrasound, CT/MRI cannot reliably detect micrometastasis, and PET/ CT will not detect lymph node spread $<10 \mathrm{~mm}(4)$. However, our review suggests that use of novel MRI contrast agents can be helpful in the detection of ILNM in SCC of the penis.

More novel elements predicting the metastasis of penile SCC to inguinal lymph nodes are the biochemical factors in the form of tumor markers and serum tests outlined above. Certainly, inflammation plays some role in both the initiation and movement of primary penile SCC tumors to lymph nodes, as $\mathrm{Hu}$ et al. conclusively identified NLR, CRP, and PD-L1 as predictors of LNM (2). Neutrophilia and lymphopenia represent a systemic inflammatory response and an active immune response. Increased NLR has been shown to predict poor prognosis in castration-resistant prostate cancer, cervical adenocarcinoma, lung cancer, and esophageal carcinoma and is known to be an independent predictor of overall survival in SCC of the penis $(2,27)$. Similarly, CRP levels have been shown to predict poor prognosis in penile SCC patients, but mixed evidence exists for their ability to predict specifically ILNM $(22,28$, 29). The transmembrane protein PD-L1 is important in the prognosis of penile SCC because of its ability to suppress the host immune system. High expression of this gene is related to increased LNM and poor prognosis, but it also serves as a common target for immunotherapy, reinforcing its theoretical benefit in penile cancer (2). Su et al. describe a case of metastatic recurrent SCC of the penis with PD-L1 expression $>10 \%$ with positive response to immunotherapy with Toripalimab. Effective immunotherapy is crucial as $62 \%$ of patients are PD-L1 overexpressers, which is associated with metastasis and poor clinical outcome (30). SCC-Ag is another marker better-studied in SCC of the cervix, with varying individual results for prediction of LNM vs. solely tumor burden in SCC of the penis (31-33). However, Hu et al. conclusively showed with meta-analysis of available evidence that its elevation serves as a predictor of LNM in SCC of the penis (2). Markers that have been studied on a very limited basis (single studies) include ID1 and SOD2, both of which clearly warrant further research before their differential expression can definitively be called predictive of LNMs. However, the establishment of biomarkers as both predictors of metastases and therapeutic targets is crucial, as these tumor and serum markers are fairly easily obtained in addition to current staining, and can provide prognostic value guiding therapy as well as immunotherapeutic targets.

Obvious limitations with this review include a wide variation in the methods and included patient populations of original articles and systematic reviews/meta-analyses analyzed. This complicates performing another meta-analysis using this data. Similarly, our desire to outline a host of factors (both clinicopathological and biochemical) contributing to increased risk of LNM limits our ability to perform wider data analyses. Regardless, our collection of large patient populations through review of original research/meta-analyses generates risk factors that confidently predict LNM and allow for higher clinical suspicion and more aggressive management. Limited evidence for some factors, particularly age and biochemical predictors of LNM, makes it difficult to evaluate their clinical utility at present, and further work is necessary prior to their incorporation into guidelines.

\section{CONCLUSION}

Here, we present a thorough review of available articles highlighting both clinicopathologic and biochemical factors predictive of LNM in patients with penile SCC. Although a specific nomogram is not presented, support is garnered for clinicians using clinically more aggressive grade and stage of tumors, as well as incorporation of imaging features and age of the patient, into risk stratification and decisions to sample nodes. Further, we present evidence for the use of inflammatory markers (CRP, NLR, 
PD-L1) and other tumor markers (p53, SCC-Ag, SOD2 and ID1 expression) in risk stratification. Clearly, a combination of these markers and clinical/pathological findings should be used as part of the shared decision-making model with patients suffering from SCC of the penis with potential LNM. Perhaps patients in whom clinical suspicion is high for ILNM would benefit from workup including the above blood and tumor markers as well as advanced imaging at the time of initial biopsy to support or counter the decision to perform ILND at the time of penectomy.

\section{CONFLICT OF INTEREST}

The corresponding author certifies that all conflicts of interest, including specific financial interests and relationships and affiliations relevant to the subject matter or materials discussed in the manuscript (i.e. employment/affiliation, grants or funding, consultancies, honoraria, stock ownership or options, expert testimony, royalties, or patents filed, received, or pending), are the following: DSZ, $\mathrm{AD}, \mathrm{AML}, \mathrm{AJH}$, and JC have no disclosures. PES is vice-chair and panel member of the NCCN bladder and penile cancer panel and president of the Global Society of Rare GU Tumors.

\section{DATA SHARING STATEMENT}

The data that support the findings of this study are available from the corresponding author upon reasonable request.

\section{REFERENCES}

1. Peak TC, Russell GB, Dutta R, Rothberg MB, Chapple AG, Hemal AK. A National Cancer Database-based nomogram to predict lymph node metastasis in penile cancer. BJU Int. 2019; 123:1005-10.

2. Hu J, Cui Y, Liu P, Zhou X, Ren W, Chen J, et al. Predictors of inguinal lymph node metastasis in penile cancer patients: a meta-analysis of retrospective studies. Cancer Manag Res. 2019; 11:6425-41.

3. Penile Cancer. NCCN Guidelines - 2020. [Internet]. Available at. <https://www.nccn.org/professionals/physician_gls/pdf/ penile.pdf>
4. Hakenberg OW, Compérat E, Minhas S, Necchi A, Protzel C, Watkin N, et al. EAU Guidelines on Penile Cancer 2020. European Association of Urology -EAU. [Internet]. Available at.<https://uroweb.org/wp-content/uploads/EAUGuidelines-on-Penile-Cancer-2020.pdf>

5. Qu XM, Siemens DR, Louie AV, Yip D, Mahmud A. Validation of predictors for lymph node status in penile cancer: Results from a population-based cohort. Can Urol Assoc J. 2018; 12:119-25.

6. Zhu Y, Zhang HL, Yao XD, Zhang SL, Dai B, Shen YJ, et al. Development and evaluation of a nomogram to predict inguinal lymph node metastasis in patients with penile cancer and clinically negative lymph nodes. J Urol. 2010; 184:539-45

7. Barua SK, Kaman PK, Baruah SJ, T P R, Bagchi PK, Sarma $D$, et al. Role of Diffusion-Weighted Magnetic Resonance Imaging (DWMRI) in Assessment of Primary Penile Tumor Characteristics and Its Correlations With Inguinal Lymph Node Metastasis: A Prospective Study. World J Oncol. 2018; 9:14550.

8. Fonseca AG, Soares FA, Burbano RR, Silvestre RV, Pinto LO. Human Papilloma Virus: Prevalence, distribution and predictive value to lymphatic metastasis in penile carcinoma Int Braz J Urol. 2013; 39:542-50.

9. Alkatout I, Naumann CM, Hedderich J, Hegele A, Bolenz C, Jünemann KP, et al. Squamous cell carcinoma of the penis: predicting nodal metastases by histologic grade, pattern of invasion and clinical examination. Urol Oncol. 2011; 29:774-81.

10. Termini L, Fregnani JH, Boccardo E, da Costa WH, LongattoFilho A, Andreoli MA, Costa MC, Lopes A, da Cunha IW, Soares FA, Villa LL, Guimarães GC. SOD2 immunoexpression predicts lymph node metastasis in penile cancer. BMC Clin Pathol. 2015; 15:3.

11. Lam W, Alnajjar HM, La-Touche S, Perry M, Sharma D, Corbishley $\mathrm{C}$, et al. Dynamic sentinel lymph node biopsy in patients with invasive squamous cell carcinoma of the penis: a prospective study of the long-term outcome of 500 inguinal basins assessed at a single institution. Eur Urol. 2013; 63:657-63.

12. Schubert T, Uphoff J, Henke RP, Wawroschek F, Winter A. Reliability of radioisotope-guided sentinel lymph node biopsy in penile cancer: verification in consideration of the European guidelines. BMC Urol. 2015; 15:98.

13. Dell'Oglio P, de Vries HM, Mazzone E, KleinJan GH, Donswijk $\mathrm{ML}$, van der Poel HG, et al. Hybrid Indocyanine Green99mTc-nanocolloid for Single-photon Emission Computed Tomography and Combined Radio- and Fluorescence-guided Sentinel Node Biopsy in Penile Cancer: Results of 740 Inguinal Basins Assessed at a Single Institution. Eur Urol. 2020: S0302-2838(20)30698-9. 
14. Nascimento ADMTD, Pinho JD, Júnior AALT, Larges JS, Soares FM, Calixto JRR, et al. Angiolymphatic invasion and absence of koilocytosis predict lymph node metastasis in penile cancer patients and might justify prophylactic lymphadenectomy. Medicine (Baltimore). 2020; 99:e19128.

15. Bloom JB, Stern M, Patel NH, Zhang M, Phillips JL. Detection of lymph node metastases in penile cancer. Transl Androl Urol. 2018; 7:879-86.

16. Tabatabaei S, Harisinghani M, McDougal WS. Regional lymph node staging using lymphotropic nanoparticle enhanced magnetic resonance imaging with ferumoxtran-10 in patients with penile cancer. J Urol. 2005; 174:923-7; discussion 927

17. Ottenhof SR, Vegt E. The role of PET/CT imaging in penile cancer. Transl Androl Urol. 2017;6:833-8.

18. Singh AK, Saokar A, Hahn PF, Harisinghani MG. Imaging of penile neoplasms. Radiographics. 2005; 25:1629-38.

19. Zhu Y, Zhou XY, Yao XD, Dai B, Ye DW. The prognostic significance of $p 53, \mathrm{Ki}-67$, epithelial cadherin and matrix metalloproteinase- 9 in penile squamous cell carcinoma treated with surgery. BJU Int. 2007; 100:204-8.

20. Lopes A, Bezerra AL, Pinto CA, Serrano SV, de MellO CA, Villa LL. p53 as a new prognostic factor for lymph node metastasis in penile carcinoma: analysis of 82 patients treated with amputation and bilateral lymphadenectomy. J Urol. 2002; 168:81-6.

21. Warli SM, Siregar GP. Over-expression of Ki-67 as a predictor of lymph node metastasis in penile cancer patients. F100020, 24. [Internet]. Available at. <https://f1000research. com/articles/9-289>

22. Al Ghazal A, Steffens S, Steinestel J, Lehmann R, Schnoeller TJ, Schulte-Hostede A, et al. Elevated C-reactive protein values predict nodal metastasis in patients with penile cancer. BMC Urol. 2013; 13:53.

23. Ficarra V, Akduman B, Bouchot O, Palou J, Tobias-Machado M. Prognostic factors in penile cancer. Urology. 2010; 76(2 Suppl 1):S66-73.

24. Bezerra AL, Lopes A, Santiago GH, Ribeiro KC, Latorre MR, Villa LL. Human papillomavirus as a prognostic factor in carcinoma of the penis: analysis of 82 patients treated with amputation and bilateral lymphadenectomy. Cancer. 2001; 91:2315-21

25. Zhou X, Qi F, Zhou R, Wang S, Wang Y, Wang Y, et al. The role of perineural invasion in penile cancer: a meta-analysis and systematic review. Biosci Rep. 2018; 38:BSR20180333.

26. McDougal WS, Kirchner FK Jr, Edwards RH, Killion LT. Treatment of carcinoma of the penis: the case for primary lymphadenectomy. J Urol. 1986; 136:38-41.
27. Azizi M, Peyton CC, Boulware DC, Chipollini J, Juwono T, Pow-Sang JM, et al. Prognostic Value of Neutrophil-toLymphocyte Ratio in Penile Squamous Cell Carcinoma Patients Undergoing Inguinal Lymph Node Dissection. Eur Urol Focus. 2019; 5:1085-90.

28. Steffens S, Al Ghazal A, Steinestel J, Lehmann R, Wegener G, Schnoeller TJ, et al. High CRP values predict poor survival in patients with penile cancer. BMC Cancer. 2013; 13:223.

29. Li ZS, Yao K, Li YH, Chen JP, Deng CZ, Zhao Q, et al. Clinical significance of preoperative C-reactive protein and squamous cell carcinoma antigen levels in patients with penile squamous cell carcinoma. BJU Int. 2016; 118:272-8.

30. Su X, Zhang J, Fu C, Xiao M, Wang C. Recurrent Metastatic Penile Cancer Patient with Positive PD-L1 Expression Obtained Significant Benefit from Immunotherapy: A Case Report and Literature Review. Onco Targets Ther. 2020; 13:3319-24.

31. Hungerhuber E, Schlenker B, Schneede P, Stief CG, Karl A. Squamous cell carcinoma antigen correlates with tumor burden but lacks prognostic potential for occult lymph node metastases in penile cancer. Urology. 2007; 70:975-9.

32. Laniado ME, Lowdell C, Mitchell H, Christmas TJ. Squamous cell carcinoma antigen: a role in the early identification of nodal metastases in men with squamous cell carcinoma of the penis. BJU Int. 2003; 92:248-50.

33. Touloupidis S, Zisimopoulos A, Giannakopoulos S, Papatsoris AG, Kalaitzis C, Thanos A. Clinical usage of the squamous cell carcinoma antigen in patients with penile cancer. Int J Urol. 2007; 14:174-6.

34. Maciel CVM, Machado RD, Morini MA, Mattos PAL, Dos Reis R, Dos Reis RB, et al. External validation of nomogram to predict inguinal lymph node metastasis in patients with penile cancer and clinically negative lymph nodes. Int Braz $J$ Urol. 2019; 45:671-8.

35. Slaton JW, Morgenstern N, Levy DA, Santos MW Jr, Tamboli $P$, Ro JY, et al. Tumor stage, vascular invasion and the percentage of poorly differentiated cancer: independent prognosticators for inguinal lymph node metastasis in penile squamous cancer. J Urol. 2001; 165:1138-42.

36. Ficarra V, Zattoni F, Artibani W, Fandella A, Martignoni G, Novara G, et al. Penile Cancer Project Members. Nomogram predictive of pathological inguinal lymph node involvement in patients with squamous cell carcinoma of the penis. $J$ Urol. 2006; 175:1700-4; discussion 1704-5.

37. Velazquez EF, Ayala G, Liu H, Chaux A, Zanotti M, Torres $\mathrm{J}$, et al. Histologic grade and perineural invasion are more important than tumor thickness as predictor of nodal metastasis in penile squamous cell carcinoma invading 5 to 10 mm. Am J Surg Pathol. 2008; 32:974-9. 
38. Bhagat SK, Gopalakrishnan G, Kekre NS, Chacko NK, Kumar $\mathrm{S}$, Manipadam MT, et al. Factors predicting inguinal node metastasis in squamous cell cancer of penis. World $\mathrm{J}$ Urol. 2010; 28:93-8.

39. Winters BR, Mossanen M, Holt SK, Lin DW, Wright JL. Predictors of Nodal Upstaging in Clinical Node Negative Patients With Penile Carcinoma: A National Cancer Database Analysis. Urology. 2016; 96:29-34. Erratum in: Urology. 2017; 108:243.

40. Graafland NM, Lam W, Leijte JA, Yap T, Gallee MP, Corbishley $C$, et al. Prognostic factors for occult inguinal lymph node involvement in penile carcinoma and assessment of the high-risk EAU subgroup: a two-institution analysis of 342 clinically node-negative patients. Eur Urol. 2010; 58:742-7.

41. Dai B, Ye DW, Kong YY, Yao XD, Zhang HL, Shen YJ. Predicting regional lymph node metastasis in Chinese patients with penile squamous cell carcinoma: the role of histopathological classification, tumor stage and depth of invasion. J Urol. 2006; 176(4 Pt 1):1431-5; discussion 1435.

42. Emerson RE, Ulbright TM, Eble JN, Geary WA, Eckert GJ, Cheng L. Predicting cancer progression in patients with penile squamous cell carcinoma: the importance of depth of invasion and vascular invasion. Mod Pathol. 2001; 14:963-8.

43. Ramkumar A, Seshadri RA, Narayanaswamy K, Balasubramanian S. Risk factors for lymph node metastasis in clinically node-negative penile cancer patients. Int $\mathrm{J}$ Urol. 2009; 16:383-6; discussion 386-7.

44. Wang JY, Gao MZ, Yu DX, Xie DD, Wang Y, Bi LK, et al. Histological subtype is a significant predictor for inguinal lymph node metastasis in patients with penile squamous cell carcinoma. Asian J Androl. 2018; 20:265-9.
45. Ficarra V, Martignoni G, Maffei N, Cerruto MA, Novara G, Cavalleri S, et al. Predictive pathological factors of lymph nodes involvement in the squamous cell carcinoma of the penis. Int Urol Nephrol. 2002; 34:245-50.

46. Zhou X, Zhong Y, Song L, Wang Y, Wang Y, Zhang Q, et al. Nomograms to predict the presence and extent of inguinal lymph node metastasis in penile cancer patients with clinically positive lymph nodes. Transl Androl Urol. 2020; 9:621-8.

47. Unadkat P, Fleishman A, Olumi A, Wagner A, Chang P, Kim S, et al. MP11-04 contemporary incidence and predictors of occult inguinal lymph node metastases in men with cn0 penile cancer. J Urol. 2020, e136. [Internet]. Available at. <https://www.auajournals.org/doi/10.1097/ JU.0000000000000831.04>

48. Guimarães GC, Lopes A, Campos RS, Zequi Sde C, Leal ML, Carvalho AL, et al. Front pattern of invasion in squamous cell carcinoma of the penis: new prognostic factor for predicting risk of lymph node metastases. Urology. 2006; 68:148-53.

49. Luchey A, Espiritu P, Gopman J, Agarwal G, Pow-Sang JM, Sexton WJ, et al. Inguinal lymph node dissection for penile cancer: Predictors of lymph node metastasis. J Clin Oncol. 2014;32: Issue 4_suppl. Available at. <https://ascopubs.org/ doi/abs/10.1200/jc0.2014.32.4_suppl.386>

50. Li K, Sun J, Wei X, Wu G, Wang F, Fan C, et al. Prognostic value of lymphovascular invasion in patients with squamous cell carcinoma of the penis following surgery. BMC Cancer. 2019; 19:476.

51. Hu X, Chen M, Li Y, Wang Y, Wen S, Jun F. Overexpression of ID1 promotes tumor progression in penile squamous cell carcinoma. Oncol Rep. 2019; 41:1091-1100.

Correspondence address:

Ali Hajiran, MD

Department of Genitourinary Oncology

H. Lee Moffitt Cancer Center \& Research Institute 12902 Magnolia Drive Tampa, FL 33612, USA E-mail: ali.hajiran@moffitt.org 